\title{
Sistem Informasi Warehouse Management System (WMS) Pada PT. Citra Banjar Abadi
}

\author{
Nina Rahayu ${ }^{1}$, Yazid Ma'ruf ${ }^{2}$, Aditya Sunarsa ${ }^{3}$ \\ ${ }^{1,3}$ Program Studi Sistem Komputer Universitas Raharja, \\ ${ }^{2}$ Program Studi Sistem Informasi Universitas Raharja \\ E-mail: ${ }^{1}$ nina.rahayu@ raharja.info, ${ }^{* 2}$ yazid@ raharja.info, ${ }^{3}$ aditya.sunarsa@ raharja.info
}

\begin{abstract}
Abstrak
PT.Citra Banjar Abadi merupakan perusahaan yang bergerak dibidang pendistribusian barang Raw Material untuk kebutuhan pembuatan menara saluran udara tegangan ekstra tinggi atau yang kita kenal dengan nama SUTET. Permasalahan yang terjadi di PT.Citra Banjar Abadi saat ini untuk sistem informasi warehousenya, terutama untuk pengolahan datanya masih menggunakan Ms.Excel, sehingga memiliki resiko dari segi keamanan dan kurang terjaminnya keakuratan data barang, dll. Metode analisa sistem yang digunakan yakni metode SWOT yang cocok diterapkan pada penelitian ini, kemudian metode perancangan sistemnya digambarkan dengan diagram-diagram UML, bahasa pemrograman dengan PHP, basis data menggunakan MySQL serta software pembuatan program dengan Sublime dan XAMPP. Penerapan sistem informasi Warehouse Management System (WMS) yang dibuat dari penelitian ini diharapkan menjadi solusi yang tepat untuk menyelesaikan permasalahan yang ada, karena tujuan diterapkannya WMS ini agar proses bisnis yang berlangsung menjadi lebih efektif, efisien waktu dan sumber daya.
\end{abstract}

Kata Kunci: Sistem Informasi, Warehouse Management System (WMS).

\begin{abstract}
PT. Citra Banjar Abadi is a company engaged in the distribution of Raw Material goods for the needs of making extra high voltage overhead line towers or what we know as SUTET. The problems that occur at PT. Citra Banjar Abadi at this time is for the warehouse information system, especially for data processing, it still uses Ms. Excel, so it has risks in terms of security and lack of guaranteed accuracy of data items, etc. The system analysis method used is the SWOT method which is suitable to be applied in this research, then the system design method is described by UML diagrams, programming language with PHP, database using MySQL and programming software with Sublime and XAMPP. The application of the Warehouse Management System (WMS) information system created from this research is expected to be the right solution to solve existing problems, because the purpose of implementing this WMS is to make ongoing business processes more effective, time and resource efficient.
\end{abstract}

Keywords: Information System, Warehouse Management System (WMS).

\section{PENDAHULUAN}

Teknologi informasi berbasis komputer saat ini merupakan hal terpenting yang tidak bisa kita lewatkan, begitupun pada dunia industri dan perusahaan, yang harus meningkatkan performanya, terutama untuk peningkatan kinerja dan hasil kerjanya. Namun demikian, masih banyak juga perusahaan yang belum meng-upgrade sistem kerja dan sistem informasinya agar berbasis Computerized. PT.Citra Banjar Abadi merupakan perusahaan yang bergerak dibidang pendistribusian barang Raw Material untuk kebutuhan pembuatan menara saluran udara 
tegangan ekstra tinggi atau yang kita kenal dengan nama SUTET. Permasalahan yang terjadi di PT.Citra Banjar Abadi saat ini untuk sistem informasi Warehousenya, terutama untuk pengolahan datanya masih menggunakan Ms.Excel, sudah menggunakan aplikasi komputer namun belum maksimal hasilnya karena Ms.Excel kurang dapat menangani Big Datanya PT.Citra Banjar Abadi, sehingga memiliki resiko dari segi keamanan, kurang terjaminnya keakuratan data barang dan lain-lain. Untuk itulah maka penelitian ini dibuat, agar dapat meminimalkan permasalahan yang ada. Metode analisa sistem yang cocok diterapkan pada penelitian ini yakni menggunakan metode SWOT dan metode perancangan sistemnya digambarkan dengan diagram-diagram UML dengan software Visual Paradigm, bahasa pemrograman dengan PHP, basis data menggunakan MySQL serta software pembuatan program dengan Sublime dan XAMPP. Penerapan sistem informasi Warehouse Management System (WMS) yang dibuat dari penelitian ini diharapkan menjadi solusi yang tepat untuk menyelesaikan permasalahan yang ada, karena tujuan diterapkannya Warehouse Management System (WMS) ini agar proses bisnis yang berlangsung pada PT.Citra banjar Abadi menjadi lebih efektif, efisien waktu dan efisien pula dari sisi sumber daya manusianya.

\section{LITERATURE REVIEW}

Literature review pada penelitian ini merangkum 5 (lima) sumber referensi yang mendukung menyempurnakan penelitian sistem informasi Warehouse Management System (WMS) untuk PT.Citra Banjar Abadi. Merujuk kepada definisi Literature Review yang berarti suatu "Action to review and re-examine a library" (Azizah: 2017), melakukan review/ulasan dan memeriksa kembali sumber pustaka. Berikut ini kelima sumber referensi pendukung penelitian ini :

1. Research yang dilakukan oleh I Gusti Ayu Putu Arika Putri dan I Nyoman Nurcaya (2019), dengan judul research-nya: "Penerapan WMS pada PT.Uniplastindo Interbuana Bali". Perusahaan ini memfokuskan pada bidang Material Handling dan saat itu memiliki permasalahan pada biaya penempatan material handling yang cukup tinggi, sehingga dibuatlah penelitian ini. Diterapkan WMS (Warehouse Management System) pada PT.Uniplastindo Interbuana Bali ini mampu menekan biaya penempatan material handling, lebih efisien waktu dan memiliki keakuratan penempatan/posisi letak material handlingnya.

2. Research yang dilakukan oleh Ingrid Valentina dan Yudhi kurniawan (2020), dengan judul research-nya: "Warehouse Management System untuk IKM Center Kabupaten Malang dilengkapi Profiling IKM Center". Penelitian ini dibuat dengan tujuan untuk pendataan kegiatan-kegiatan UMKM yang tersebar pada kabupaten Malang. Hal ini dilakukan untuk meminimalisasi redundansi data, mencegah Human Error dan meningkatkan keakuratan laporan kegiatan UMKM Kabupaten Malang setiap bulannya.

3. Research yang dilakukan oleh Bella Fauziah, Gunawan Abdillah dan Faiza Renaldi (2017), dengan judul research-nya: "Perancangan dan Implementasi WMS pada PT.Feedmill Indonesia". Tujuan penelitiannya untuk me-Manage Every Warehousing Process terutama pada proses-proses pergudangan yang dimiliki PT.Feedmill Indonesia, khususnya untuk pengelolaan administrasi pergudangan, transaksi pergudangan, integrasi antar gudang; gudang cabang dan gudang pusat PT.Feedmill Indonesia serta untuk Laporan Pergudangan yang akurat.

4. Research yang dilakukan oleh James Lee dan Herry Christian Palit (2017), dengan judul research-nya: "Perancangan Gudang dan Sistem Manajemen Pergudangan di UD.Wirakarya". Tujuan penelitian ini untuk perapihan sistem penataan gudang lama dan perancangan penataan gudang baru yang dimiliki oleh UD.Wirakarya agar tidak timbul lagi permasalahan penataan gudang yang dapat berdampak pada jumlah stok barang digudang. 
5. Research yang dilakukan oleh Abi Prasidi dan Lis Lesmini (2019), dengan judul research-nya: "Ketepatan Waktu Pendistribusian Barang Pada WMS di PT.Ceva Logistics". Tujuan penelitian ini yakni untuk kelancaran sistem distribusi pergudangan dengan metode WMS dalam upaya untuk mengatasi kendala yang terjadi saat proses pendistribusian barang di PT.Ceva Logistics.

Dari Literature Review diatas, penelitian ini mempunyai keunggulan di dalam mengatasi permasalahan yang ada pada PT.Citra Banjar Abadi dengan pembuatan sistem yang mencakup seluruh proses bisnis dan aktivitas usaha yang terkait dan sesuai dengan kebutuhan PT.Citra Banjar Abadi.

\section{METODE PENELITIAN}

\section{Metode Pengumpulan Data}

Metode Observasi, Wawancara, Studi Pustaka merupakan 3 (tiga) metode yang dipilih di dalam pengumpulan data penelitian. Observasi merupakan metode pengamatan secara langsung pada tempat/lokasi penelitian yang dalam hal ini pada PT.Citra Banjar Abadi. Untuk wawancara dilakukan secara langsung pada Stakeholder PT.Citra Banjar Abadi yakni Bpk. Adhityan Muslim, S.Kom. Untuk sumber referensi penelitian ini, selain dari Literature Review juga diambil dari sumber lain seperti Buku, Paper Jurnal dari Google Scholar, dll.

\section{Metode Analisa Sistem}

Metode analisa sistem yang dipilih dan diterapkan pada penelitian ini yakni metode SWOT yang akan dijabarkan lengkap pada gambar dibawah ini :

Tabel 1. Analisa SWOT

\begin{tabular}{|c|c|c|}
\hline INTERNAL & $\begin{array}{c}\text { Strengths }(\mathbf{S}) \\
\text { Kekuatan }\end{array}$ & $\begin{array}{c}\text { Weaknesses (W) } \\
\text { Kelemahan }\end{array}$ \\
\hline EKSTERNAL & $\begin{array}{l}\text { 1. Tersedia fasilitas } \\
\text { komputer serta sarana } \\
\text { pendukung seperti } \\
\text { akses internet. } \\
\text { 2. SDM yang mumpuni } \\
\text { dalam dasar bidang } \\
\text { komputer. }\end{array}$ & $\begin{array}{l}\text { 1. Masih semi komputerisasi } \\
\text { yaitu menggunakan } \\
\text { Ms.Excel. } \\
\text { 2. Memakan waktu dalam } \\
\text { proses cek ketersediaan } \\
\text { barang. } \\
\text { 3. Sering terjadinya kesalahan } \\
\text { dalam penginputan barang. } \\
\text { 4. Keakuratan data yang } \\
\text { kurang terjamin. }\end{array}$ \\
\hline
\end{tabular}




\begin{tabular}{|c|c|c|}
\hline Onnortwnitios & SO & WO \\
\hline 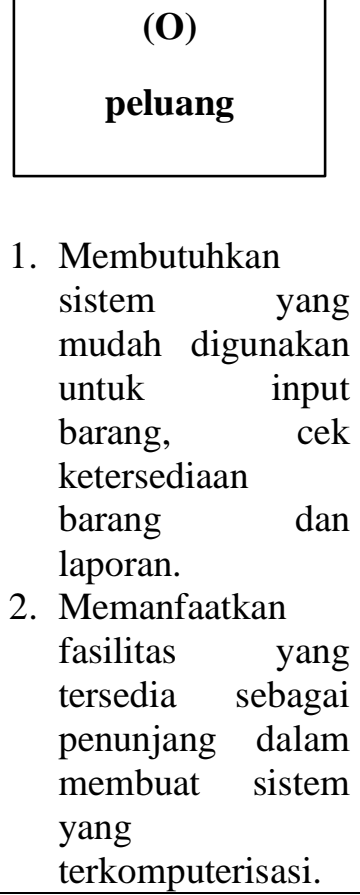 & $\begin{array}{l}\text { 1. Menciptakan sebuah } \\
\text { sistem } \\
\text { terkomputerisasi } \\
\text { berbasis web yang } \\
\text { dapat membantu staff } \\
\text { gudang dalam } \\
\text { mencari atau melihat } \\
\text { stok barang yang } \\
\text { tersedia secara akurat. } \\
\text { 2. Merancang sistem } \\
\text { informasi yang akurat } \\
\text { terutama dalam } \\
\text { mendata barang } \\
\text { masuk dan barang } \\
\text { keluar. }\end{array}$ & $\begin{array}{l}\text { 1. Menciptakan sebuah sistem } \\
\text { persediaan barang yang } \\
\text { dapat menaungi semua } \\
\text { berkas yang bersifat } \\
\text { komputerisasi. } \\
\text { 2. Menciptakan sistem yang } \\
\text { dapat menghasilkan laporan } \\
\text { secara otomatis. }\end{array}$ \\
\hline & ST & WT \\
\hline Ancaman & \multirow{2}{*}{$\begin{array}{l}\text { 1. } \begin{array}{lr}\text { Menciptakan } & \text { sistem } \\
\text { yang } & \text { dapat } \\
\text { terintegrasi } & \text { kedalam } \\
\text { database } & \text { secara } \\
\text { online. } & \\
\text { 2. } & \begin{array}{l}\text { Memperbarui } \\
\text { yang masih }\end{array} \\
& \text { semi } \\
\text { komputerisasi } & \\
\text { menjadi } & \\
\text { terkomputerisasi } \\
\text { dengan baik. }\end{array}\end{array}$} & \multirow{2}{*}{$\begin{array}{l}\text { 1. Membuat sistem yang } \\
\text { memberikan kemudahan } \\
\text { dalam hal pendataan } \\
\text { ketersediaan barang dalam } \\
\text { gudang. } \\
\text { 2. Perlu penyimpanan yang } \\
\text { baik yaitu dengan } \\
\text { menggunakan database. }\end{array}$} \\
\hline $\begin{array}{l}\text { 1. Resiko terjadinya } \\
\text { human error. } \\
\text { 2. Rumitnya mencari } \\
\text { ketersediaan } \\
\text { barang. }\end{array}$ & & \\
\hline
\end{tabular}

\section{Metode Perancangan Sistem}

Untuk metode Perancangan sistem yang diterapkan pada penelitian ini melibatkan beberapa aplikasi seperti : Penggunaan 4 (empat) jenis diagram UML, yakni Use Case Diagram, Activity diagram, Sequence Diagram, Class diagram UML dengan perangkat lunak Visual Paradigm. Bahasa pemrograman PHP, Basis data MySQL, Software pembuatan program dengan Sublime dan XAMPP, penggunaan kesemuanya ini untuk build Warehouse Management System (WMS) PT.Citra Banjar Abadi.

\section{Metode Pengujian Sistem}

Untuk metode pengujian sistem informasi Warehouse Management System (WMS) ini menggunakan pengujian Kotak Hitam, atau yang lebih familiar dikenal dengan nama Blackbox Testing, yang dijabarkan pada tabel dibawah ini : 
Tabel 2. Blackbox Testing

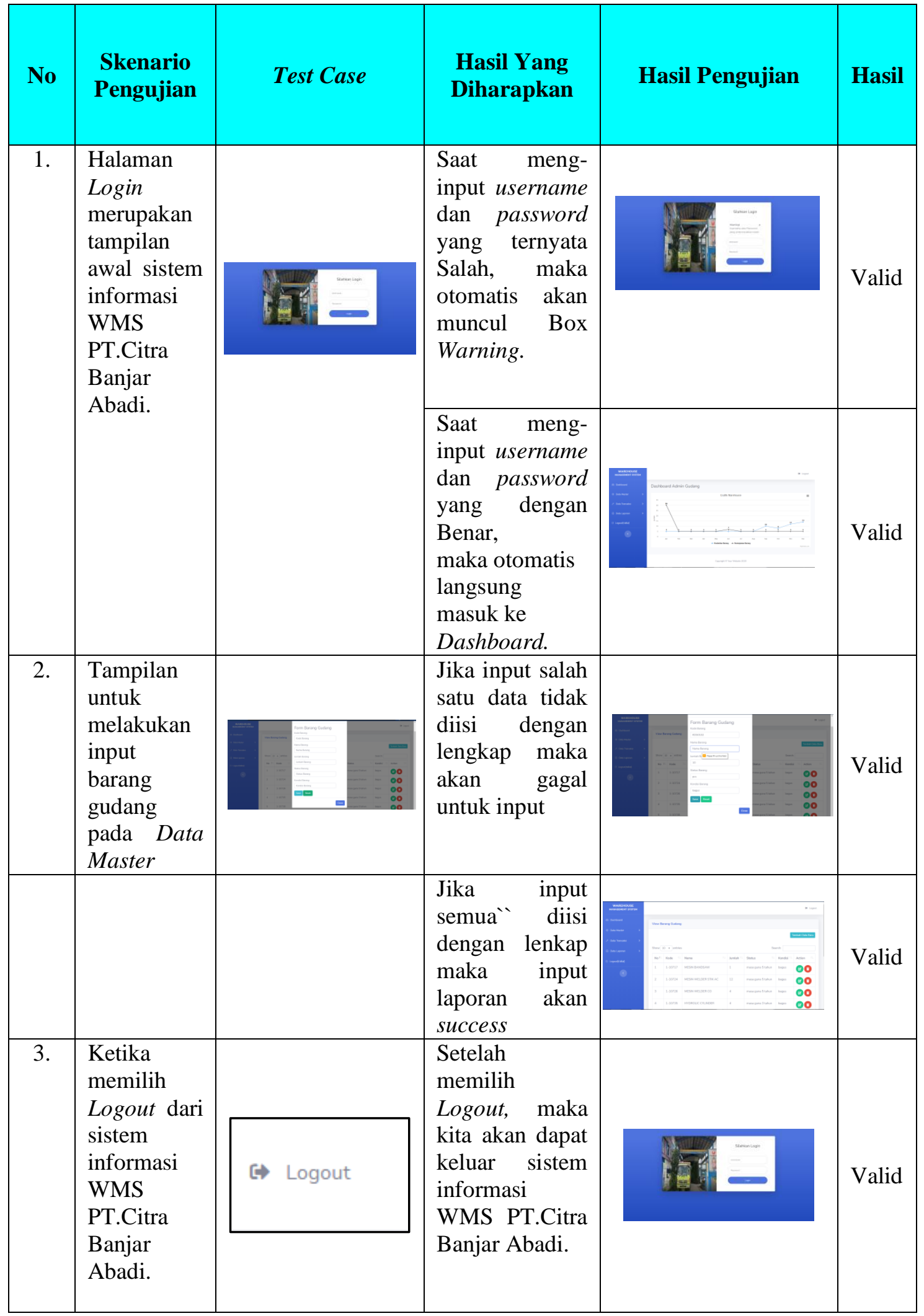




\section{HASIL DAN PEMBAHASAN}

Hasil dan pembahasan ini digambarkan proses bisnis Warehouse Management System (WMS) PT.Citra Banjar Abadi melalui diagram-diagram UML yang secara detail tergambar di bawahnya :

\section{Use Case Diagram sistem usulan Kepala Gudang}

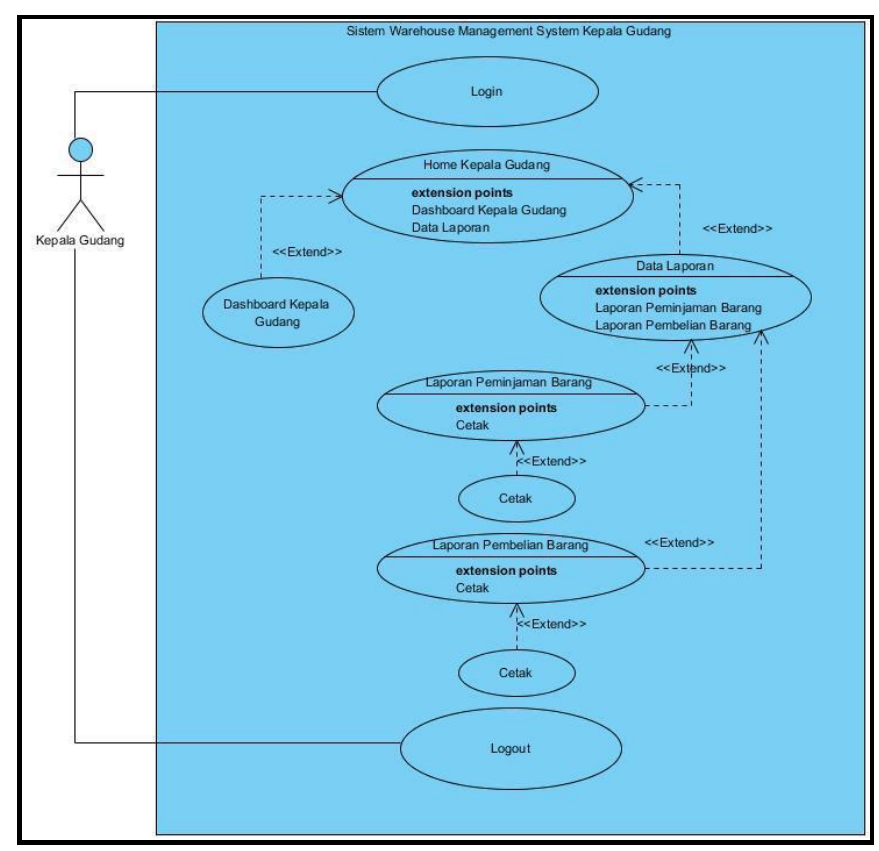

Gambar 1. Use Case Diagram sistem usulan Kepala Gudang.

Penjelasan gambar 1 :

a. 1 (satu) sistem yaitu Sistem Informasi Warehouse Management System (WMS) PT.Citra Banjar Abadi dan yang mengakses kegiatan ialah Kepala Gudang.

b. 1 (satu) actor, yaitu Kepala Gudang.

c. 9 (sembilan) Use Case yang dilakukan oleh actor Kepala Gudang tersebut.

\section{Activity Diagram sistem usulan Kepala Gudang}

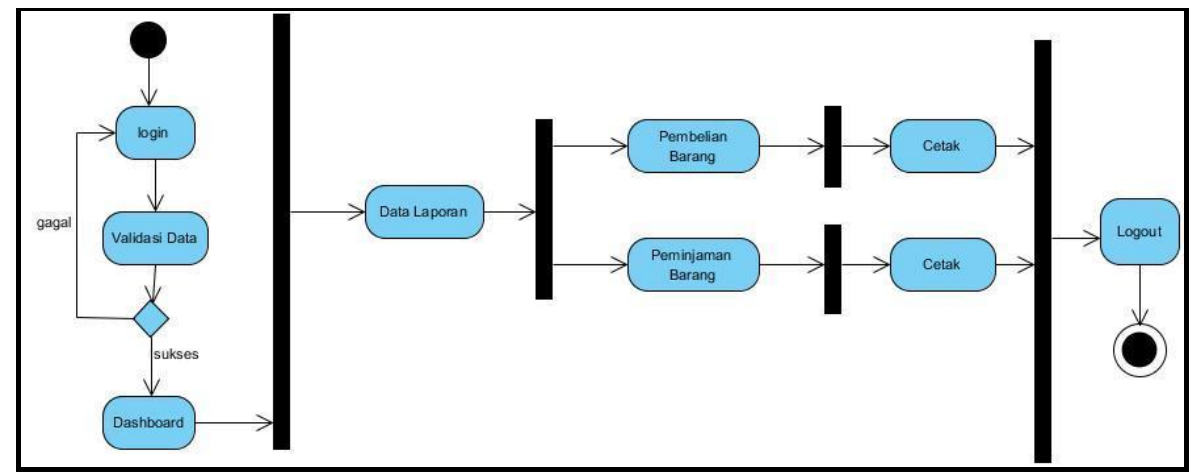

Gambar 2. Activity Diagram sistem usulan Kepala Gudang

Penjelasan gambar 2 : 
a. 1 (satu) Initial Node yang merupakan node awal.

b. 9 (sembilan) Action yang menggambarkan aktivitas yang dilakukan Actor.

c. 1 (satu) Decision Node yang menyatakan gagal dan sukses.

d. 5 (lima) Fork Node dan 1 (satu) Final Node yang merupakan node finish/akhir.

\section{Sequence Diagram sistem usulan Kepala Gudang}

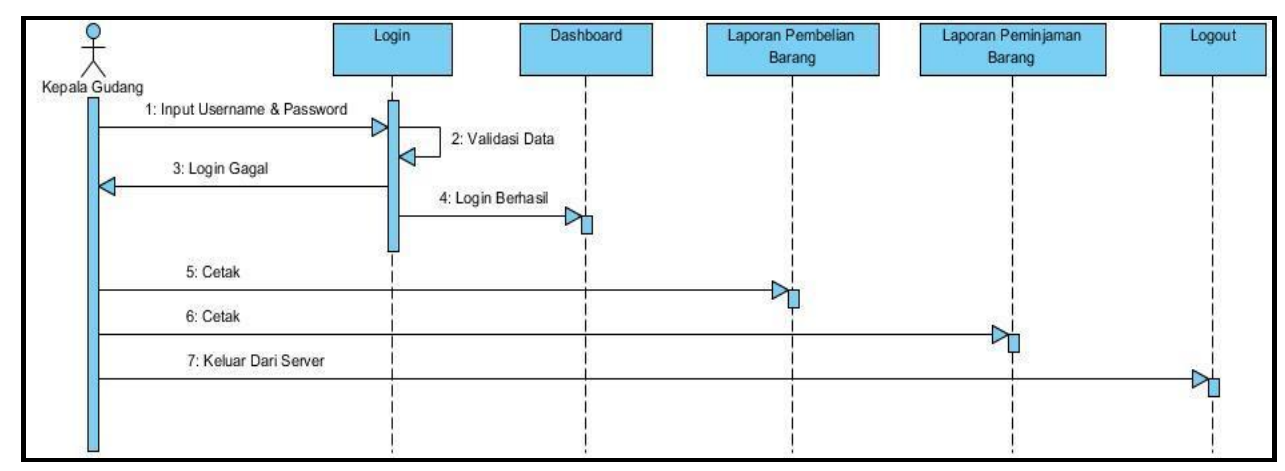

Gambar 3. Sequence Diagram sistem usulan Kepala Gudang

Penjelasan gambar 3 :

a. 1 (Satu) aktor, yaitu Kepala Gudang.

b. 5 (Lima) Life Line yang terdiri dari Login, Dashboard, Laporan Pembelian Barang, Laporan Peminjaman Barang dan Logout.

c. 7 (Tujuh) Massage, yang terdiri dari Input Username \& Password, Validasi Data, Login Gagal, Login Berhasil, Cetak Laporan Pembelian barang, Cetak Laporan Peminjaman Barang, sampai kepada Keluar dari Server.

\section{Class Diagram Database Warehouse Management System (WMS) PT.Citra Banjar Abadi}

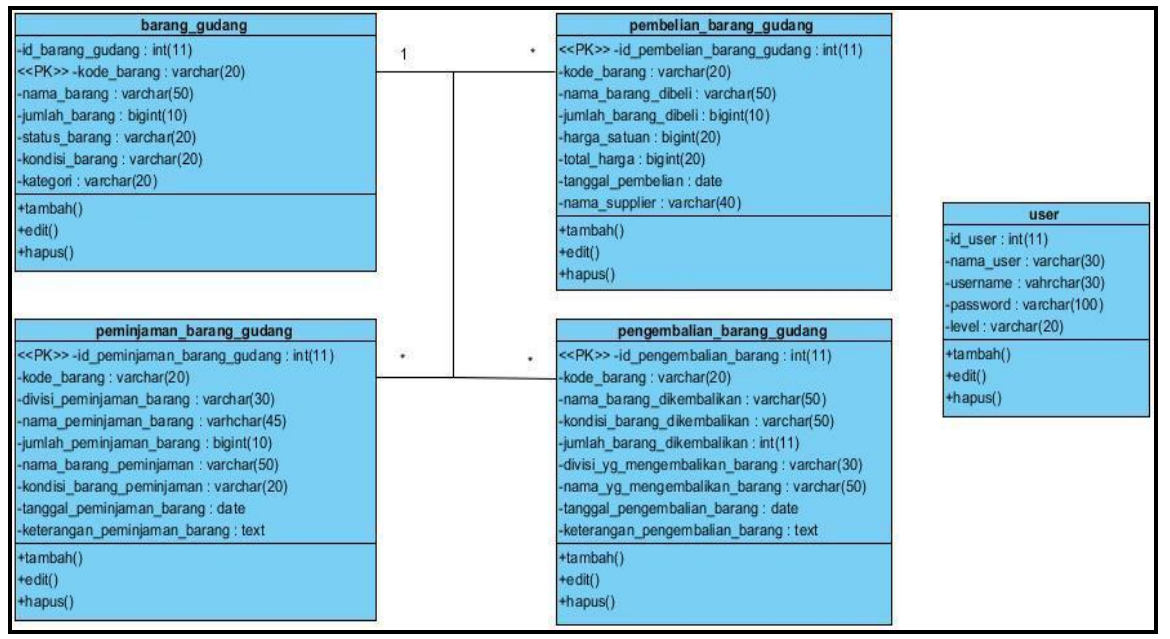

Gambar 4. Class Diagram Database Warehouse Management System (WMS) 


\section{Rancangan Program}

\section{Tampilan Halaman Login}

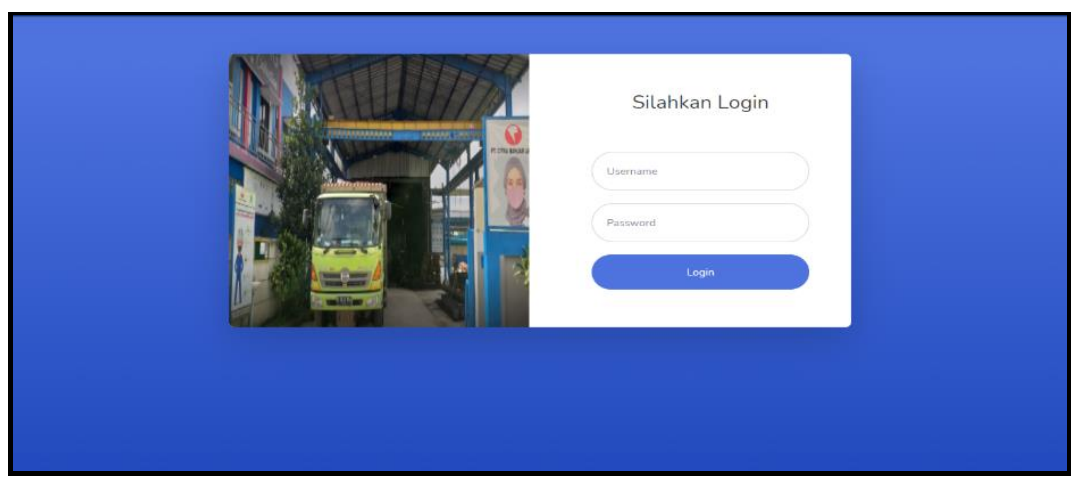

Gambar 5. Tampilan Halaman Login

Tampilan halaman login memperlihatkan tampilan awal sistem sebelum masuk ke halaman utama sistem, anda akan melihat tulisan "Silahkan Login" yang berarti anda dapat langsung memasukkan Username dan Password dan dapat segera menuju halaman utama sistem informasi WMS PT.Citra Banjar Abadi.

\section{Tampilan Dashboard}

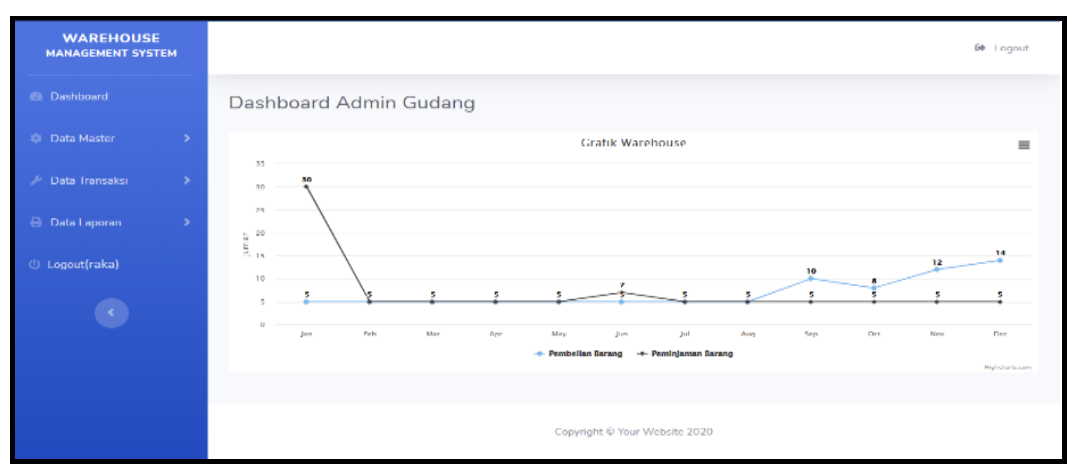

Gambar 6. Tampilan Dashboard

Tampilan Dashboard menyajikan halaman yang didalamnya terdapat grafik Pembelian Barang dan Peminjaman Barang Raw Material dalam jangka 1 tahun.

\section{Tampilan Data Master Barang Gudang}

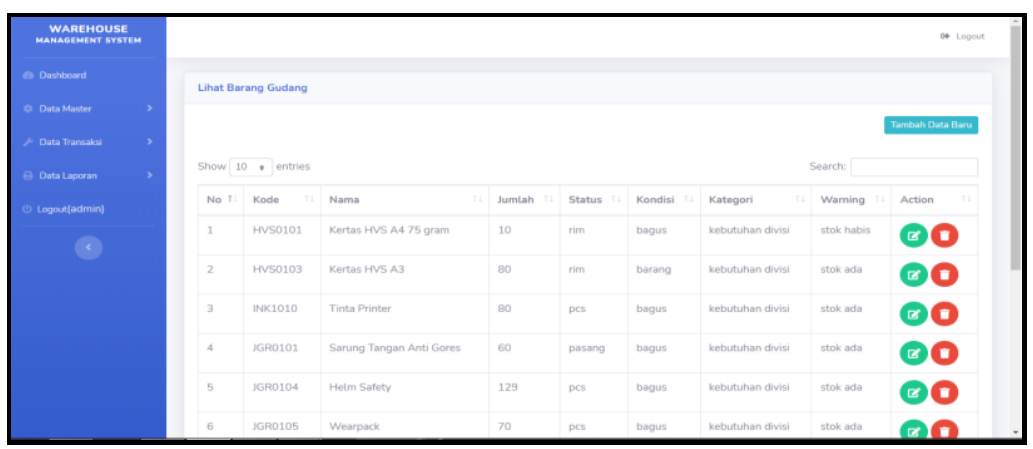

Gambar 7. Tampilan Data Master Barang Gudang 
Tampilan diatas adalah tampilan dari halaman Data Master untuk mengontrol ketersediaan barang yang ada di gudang.

\section{Tampilan Data Master Barang Gudang Asset}

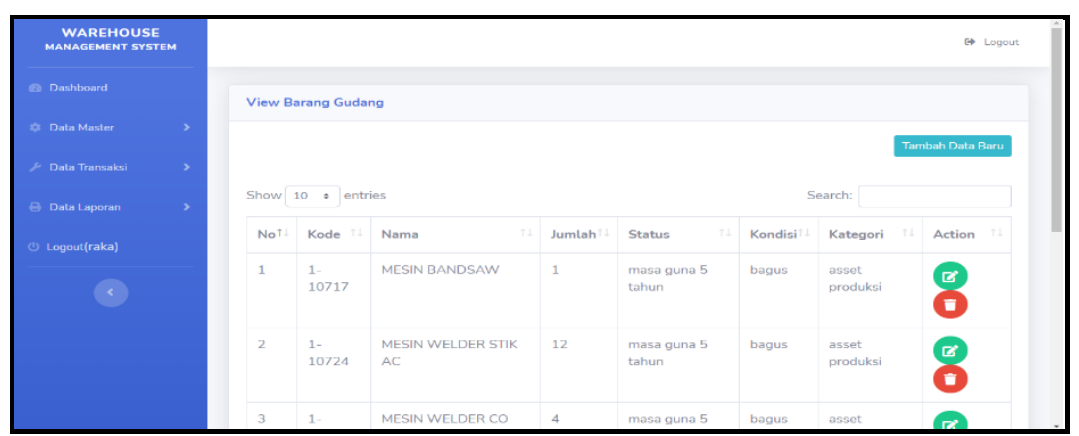

Gambar 8. Tampilan Data Master Barang Gudang Asset

Tampilan Data Master Barang Gudang Asset untuk mengontrol ketersediaan Asset divisi produksi yang ada di gudang.

\section{Tampilan Data Master User}

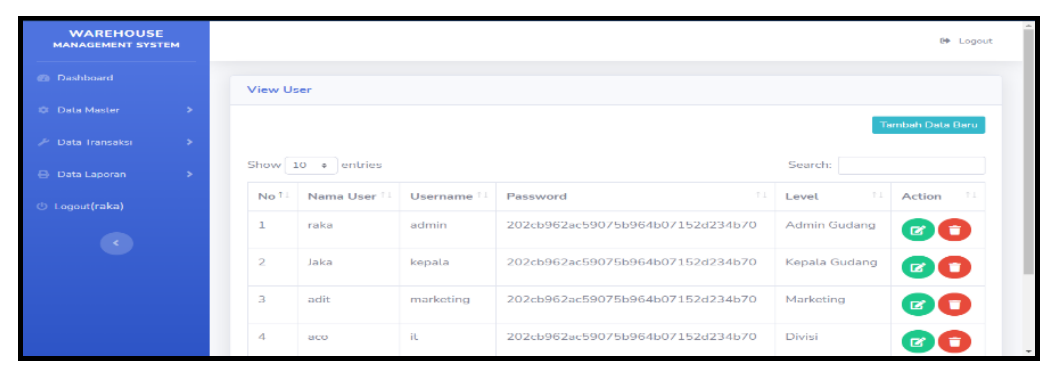

Gambar 9. Tampilan Data Master User

Tampilan diatas merupakan tampilan Data Master View User.

\section{Tampilan Data Transaksi Pembelian Barang}

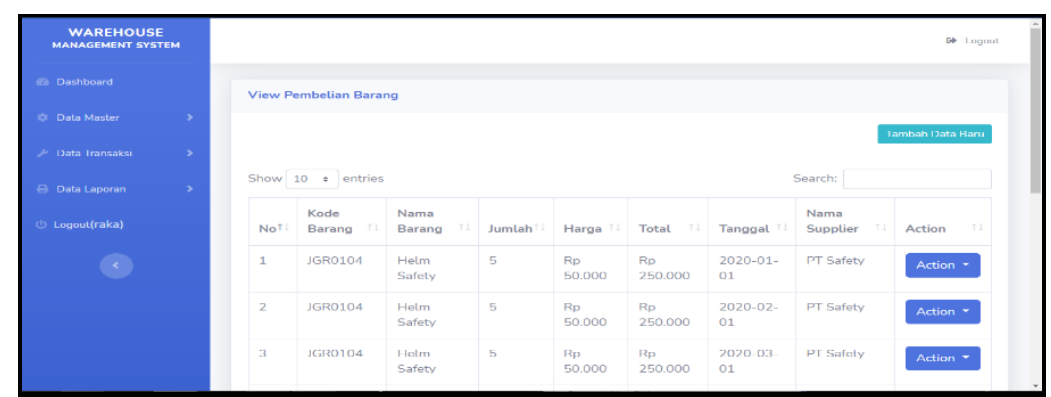

Gambar 10. Tampilan Data Transaksi Pembelian Barang

Tampilan Data Transaksi Pembelian Barang digunakan ketika stok barang gudang sudah mau habis. 


\section{Tampilan Data Transaksi Peminjaman Barang}

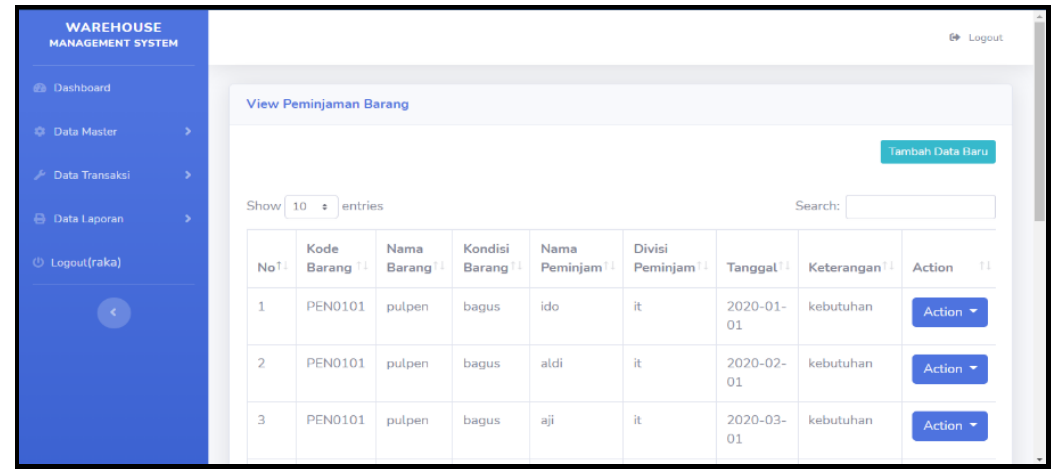

Gambar 11. Tampilan Data Transaksi Peminjaman Barang

Tampilan Data Transaksi Peminjaman Barang digunakan ketika Divisi melakukan transaksi peminjaman barang gudang.

\section{Tampilan Data Transaksi Pengembalian Barang}

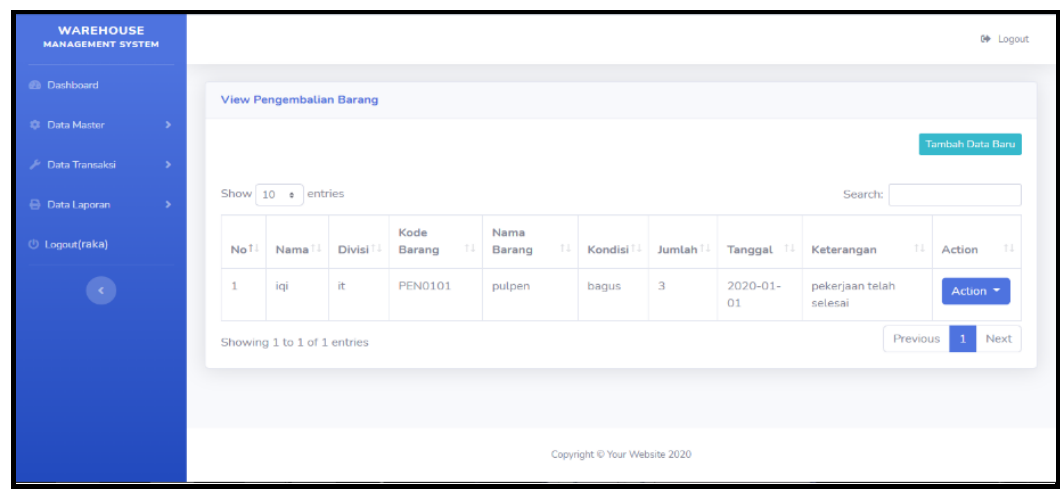

Gambar 12. Tampilan Data Transaksi Pengembalian Barang

Tampilan Data Transaksi Pengembalian Barang digunakan ketika Divisi melakukan transaksi pengembalian barang gudang.

\section{KESIMPULAN}

Kesimpulan dari penelitian ini yakni dibuatnya sistem informasi Warehouse Management System (WMS) untuk PT.Citra Banjar Abadi ini sebagai salah satu alternatif pemecahan masalah yang terjadi dalam hal pengolahan data barang Raw Material yang saat itu masih beresiko data-data yang masuk kurang aman dan kurang akurat. Penerapan sistem informasi Warehouse Management System (WMS) yang dibuat dari penelitian ini diharapkan menjadi solusi yang tepat untuk menyelesaikan permasalahan yang ada, karena tujuan diterapkannya Warehouse Management System (WMS) ini agar proses bisnis pendistribusian barang Raw Material pada PT.Citra Banjar Abadi yang berlangsung menjadi lebih efektif, efisien waktu dan sumber daya. Sistem informasi Warehouse Management System (WMS) ini dapat digunakan untuk meningkatkan performa pergudangan/Warehouse PT.Citra Banjar Abadi. 


\section{SARAN}

Disarankan agar Sistem informasi Warehouse Management System (WMS) yang telah diimplementasikan ini dapat terus dikembangkan lebih lanjut sehingga dapat terus memberikan manfaat yang besar untuk PT.Citra Banjar Abadi.

\section{DAFTAR PUSTAKA}

[1] Albar, F. M., Hardiyanti, S., \& Ramadhona, K. R. A. (2017). Inventarisasi Manajemen Aset Berbasis Online Pada Pd. bpr Kerta Raharja Cabang Balaraja. Journal Sensi, 3(2), 252-262.

[2] Fauziah, B. S., Abdillah, G., \& Renaldi, F. (2017). PERANCANGAN DAN IMPLEMENTASI WAREHOUSE MANAGEMENT SISTEM PADA PT. FEEDMILL INDONESIA. Prosiding SNST Fakultas Teknik, 1(1).

[3] Haslindah, A., Fadhli, F., Adrianto, A., \& Mansyur, R. (2017). PENGARUH IMPLEMENTASI WAREHOUSE MANAGEMENT SYSTEM TERHADAP INVENTORY CONTROL FINISH GOOD BERBASIS BARCODE PT. DHARANA INTI BOGA. ILTEK: Jurnal Teknologi, 12(02), 1760-1763.

[4] Indriyani, S. (2020). ANALYZING THE WAREHOUSE MANAGEMENT SYSTEM AT PT. POS MANADO. Jurnal EMBA: Jurnal Riset Ekonomi, Manajemen, Bisnis dan Akuntansi, 8(4).

[5] Lee, J., \& Palit, H. C. (2017). Perancangan Gudang dan Sistem Manajemen Pergudangan di UD. Wirakarya. Jurnal Titra, 5(1), 63-70.

[6] Prasidi, A., \& Lesmini, L. (2019). Ketepatan Waktu Pendistribusian Barang Pada Warehouse Management System di PT. CEVA Logistics Tahun 2019. Jurnal Logistik Indonesia, 3(2), 68-78.

[7] Valentina, I., \& Kurniawan, Y. (2020). WAREHOUSE MANAGEMENT SYSTEM UNTUK IKM CENTER KAB. MALANG YANG DILENGKAPI PROFILING IKM CENTER. Kurawal-Jurnal Teknologi, Informasi dan Industri, 3(2), 136-147. 